\title{
We are still waiting
}

\section{A Doctor's Quest: The Struggle for Mother-and-Child Health Around the Globe \\ Gretchen Roedde, John Evans \\ Dundurn Press; 2013}

\section{I am poor.}

I do not have the freedom that you have as a woman.

One day my child was playing, the next day he had died.

I have no education.

Why are women dying giving life?

I am tired of seeing HIV as the price

of wealth.

Where are our leaders? Why have they

forgotten us?

We are still waiting.

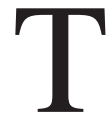
his excerpt from A Doctor's Quest was the response from Theresa, an Engan woman from Papua New Guinea, to the still absent, yet promised maternity care facility in her community. The community did its bit and built a maternity waiting home near a hospital that provided substandard maternal care. Money was secured from industry to upgrade maternal care in the hospital, house the midwife and provide medicines, but the funds vanished. The villagers were angry. They did their part.

Like the author of this absorbing book, I too am a public health physician who began my practice in remote parts of Canada then combined it with international work. I began the book wondering if it would be one of those dark tales of woe, designed to open donors' purses by shouting that global health care needs an overhaul. Thankfully, it wasn't. The book is a well-crafted, informative yet entertaining story. In the introduction, the main challenges to improvements in maternal health are clearly laid out. To illustrate these factors, stories from 15 different countries over a 22-year period are woven together to describe successes and failures from the perspective of someone yearning to learn. After 22 years of work,

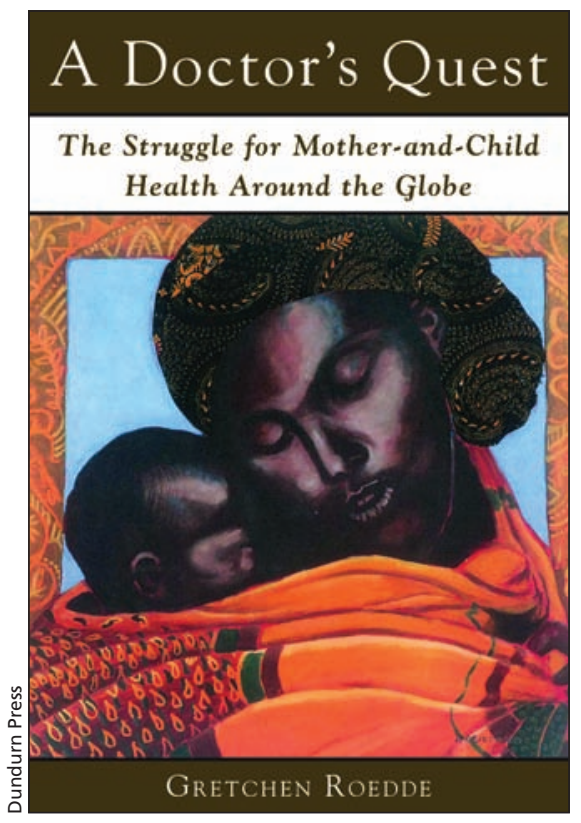

only penile covers while perusing photographs of nude women in a magazine. He stops just in time when he realizes they are discussing the women's teeth. To them, nudity is normal.

She also provides numerous depictions of corruption, such as in the Democratic Republic of the Congo where HIV medicines do not arrive at clinics but are diverted to the black market in a neighbouring country. Roedde steps beyond this challenge to describe ways to proactively involve specific, powerful organizations, a more effective intervention than fulfilling the natural desire to directly accost those involved in the corrupt behaviour.

Then there are the contrasting stories of two women, that leave the reader wondering which is right - the Tanzanian woman who describes the safety she feels when birthing at home with the help of a traditional birth attendant while surrounded by people she trusts or Sultana, a woman from Bangladesh, who underwent ten surgeries to repair her vaginal fistulas and lobbies for all women to deliver assisted by skilled birth attendants in proximity to obstetrical care.

This book is entertaining, but it also makes you think. Reducing maternal deaths and complications of labour requires money flowing to where needs exist, including gender equity and education; political will that supports maternal health in donor countries, in local countries and in the church; the inclusion of cultural reality in proposed interventions; and balancing the funding of maternal health with competing interests such as HIV. We know how to improve maternal health. Ending the struggle requires the simple solution of prioritizing it.

\section{Maureen Mayhew MD MPH}

Physician and Consultant in Global Public Health

Vancouver, BC

CMAJ 2013. DOI:10.1503/cmaj.130608 